\title{
Sustainable multi-trip periodic redesign-routing model for municipal solid waste collection network: The case study of Tehran
}

\section{Leila Mahdavi}

Amirkabir University of Technology

Saeed Mansour ( $\nabla$ s.mansour@aut.ac.ir)

Amirkabir University of Technology

Mohsen Sheikh Sajadieh

Amirkabir University of Technology

\section{Research Article}

Keywords: Municipal solid waste, periodic location routing, multi-trip vehicle routing, sustainability, redesign routing model, strategic decisions, tactical and operational issues

Posted Date: March 18th, 2021

DOI: https://doi.org/10.21203/rs.3.rs-256948/v1

License: (9) This work is licensed under a Creative Commons Attribution 4.0 International License. Read Full License

Version of Record: A version of this preprint was published at Environmental Science and Pollution Research on January 21st, 2022. See the published version at https://doi.org/10.1007/s11356-02118347-9. 
Sustainable multi-trip periodic redesign-routing model for municipal 1

solid waste collection network: The case study of Tehran

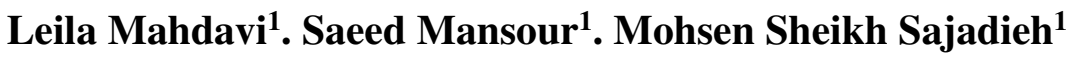

$\square \quad$ Saeed Mansour

s.mansour@aut.ac.ir

1 Department of Industrial Engineering, Amirkabir University of Technology (Tehran Polytechnic), No. 424, Hafez Ave, Valiasr Square, Tehran, Iran

Tel: $+\underline{+982164540}$ 


\section{Abstract}

Daily transportation of vehicles is one of the most important challenges in municipal solid waste

management systems in developing countries related to environmental aspects in different areas, financial

issues, and social factors. The location of transfer stations as intermediate nodes in municipal solid waste

management network affects optimal collection frequency. Here a sustainable multi-period and multi-trip

mixed-integer linear programming model was developed to redesign the intermediate transfer stations and

find optimal routes for vehicles and the best collection frequency for each municipal solid waste generation

point. Regarding the social aspect of sustainability, an extended social life cycle assessment methodology

is developed for impact assessment of redesign and routing operations. The model is applied to a real-world case study with no cooperative perspective, which could result in total cost reduction by a $66 \%$ that occurred

Keywords

Municipal solid waste, periodic location routing, multi-trip vehicle routing, sustainability, redesign routing 


\section{Introduction}

Currently, atmospheric $\mathrm{CO}_{2}$ is about $412 \mathrm{ppm}$ with an increasing pattern of 2 ppm per year (Hannan et al.

2018). The most important source that increases $\mathrm{CO}_{2}$ is transportation. According to the U.S. Environmental

Protection Agency (EPA), the transportation sector generates the largest share (about 29\%) of Green House

Gas (GHG) emissions. Besides 5\% of the global GHG emissions refereed to the perishable part of solid waste (Edalatpour et al. 2018). Daily transportation for collecting municipal solid waste (MSW) is one of the major parts of the municipal solid waste management system (MSWMS) in most developing countries.

As there are many limitations in these countries including inadequate financial resources, any stages of the

MSW management process should be done as efficient as possible (Moghadam et al. 2009). Also, environmental and health-related issues, increasing waste generation, and resource limitations make designing an efficient system for collecting MSW paramount important (Mirdar Harijani et al. 2017). In

the Brundtland Report, sustainability is defined as "the ability to meet the needs of the present without compromising the ability of future generations to meet their own needs". For referring to the sustainable systems, three dimensions of sustainability - economic, environmental, and social - need to be considered (Ramos et al. 2014).

Municipal solid waste management (MSWM) involves several of strategic, tactical, and operational decisions. Addressing two or three groups of them simultaneously will increase the accuracy of resultant decisions. To make some efficient MSWM policy, many challenging questions may arise such as: What is the best policy for redesigning an existing intermediate transfer station (ITrS) in MSWMS? How to allocate waste generation points to each of these ITrSs? In a certain period, what is the best collection frequency for generation points? What is the best route for each vehicle? How to minimize costs for such a system? How 
introduced and a mixed-integer linear programming (MILP) model was developed to find an optimal

Literature review

This section provides brief literature on relocation, sustainability, and some variants of Vehicle Routing

Problem (VRP) containing Location Routing Problem (LRP), Multi-trip, and Multi-period which are

MSWM is devoid of any in-depth research. Regarding redesign/relocation in other logistic networks,

To detect the optimal locations of MSWMS's facilities consisting of ITrSs, treatment, recycling, and 
In many developing countries, there is a problem in collecting wastes where trucks are fully utilized only

in certain days when demand is in its maximum level, while they are partially loaded on other days. This

In waste management papers, there are some research works for the examination of periodic vehicle routing problem (PVRP) which is an extension of the classical VRP that customers are serviced with different frequencies over a time horizon (Beltrami and Bodin 1974). A mathematical model for the infectious hospital waste collection problem through a two phases PVRP was proposed (Shih and Chang 2001). The

The summary of the literature in Table 1 shows that different types of optimization models in strategic, tactical, and operational issues have been developed in the field of MSWM. The surveyed articles did not

MSWM. Authors believe that there is a gap in MSWM literature about the absence of an optimization and operational issues in MSWM literature. 


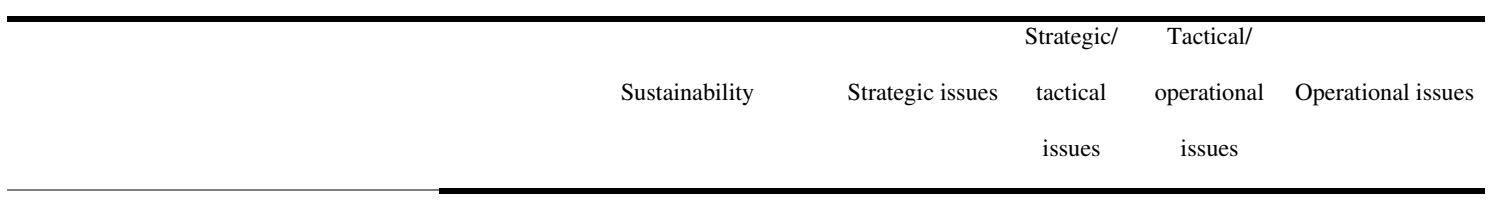

Research(s)

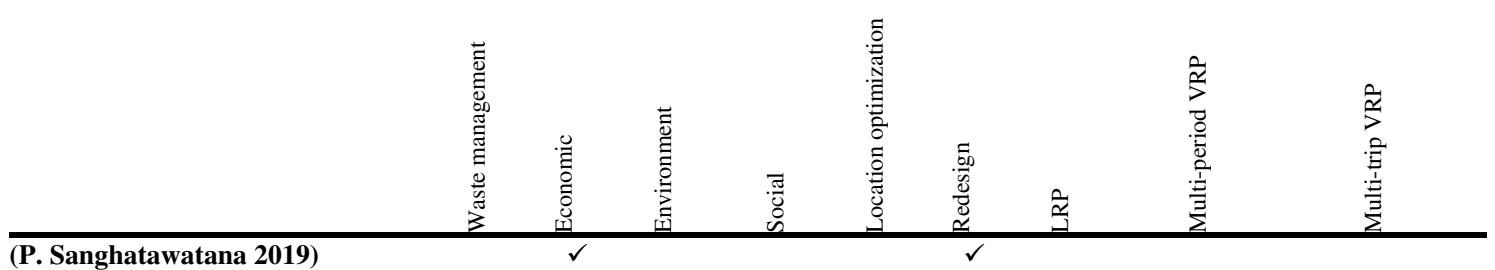

(Asefi et al. 2019)

(Erfani et al. 2017)

(Farrokhi-Asl et al. 2017)

(Rabbani et al. 2017)

(Shih and Chang 2001)

(Baptista et al. 2002)

(Matos and Oliveira 2004)

(Babaee Tirkolaee et al. 2019)

Current study
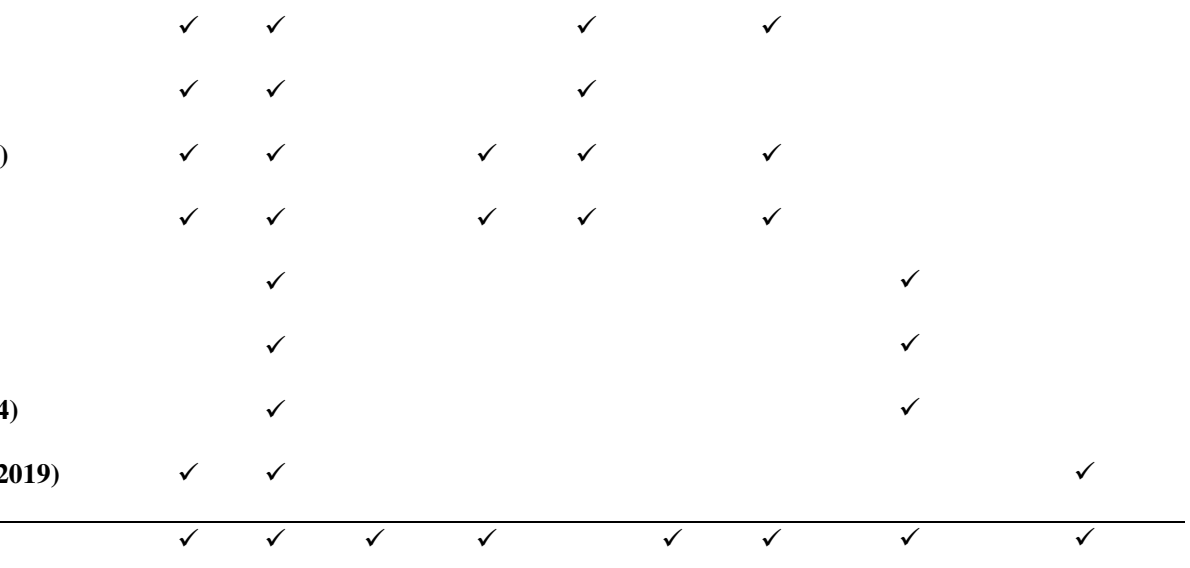

The $S M T P$-reLRP is to minimize economic and environmental costs subject to social constraints and other

adapted constraints. The proposed SMTP-reLRP simultaneously decides the customers, vehicles, and the

trips of a vehicle that should be serviced each day of a certain time horizon with considering redesign

decisions of ITrSs.

Major contributions are: (1) it introduces a MILP optimization model to consider the sustainability of

MSWMSs with strategic, tactical, and operational issues simultaneously, (2) it extends the social life cycle 
of Tehran as a real case study to show the applicability of the proposed model and it can be a solution to

\section{Problem definition and mathematical model}

Graphical representation for MSW collection VRP is provided in Fig.1(a) where the MSW collecting process starts from ITrSs as vehicles' depots and will continue until the vehicle's capacity complete. The destination of the vehicles will be the starting ITrS. This process is called a trip. In classic VRP, it is assumed that each vehicle only makes one trip, but this is not possible due to the scarcity of vehicles. For this reason, a sequence of trips must be performed by each vehicle called a journey. The network consists of two-echelon with two main different fleets, small and lightweight vehicles for the first part, and heavyweight semitrailers for the second part of the network. The lightweight vehicles and heavyweight 


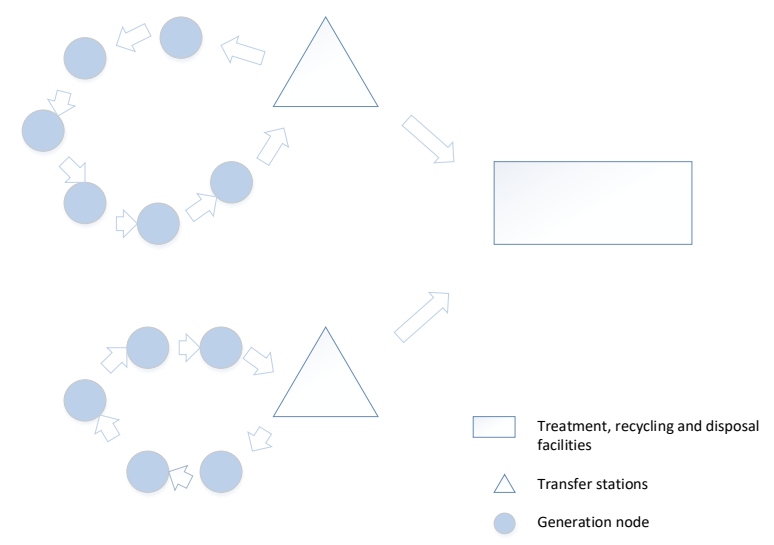

(a)

Dav\#

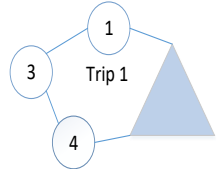

$\underline{\text { Day \# }}$

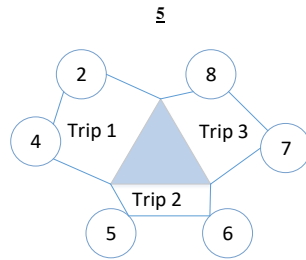

$\underline{2}$

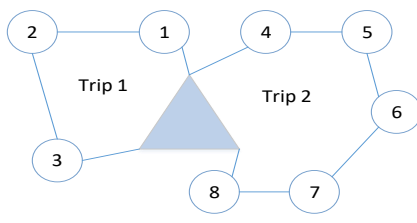

6

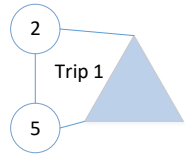

$\underline{\mathbf{3}}$

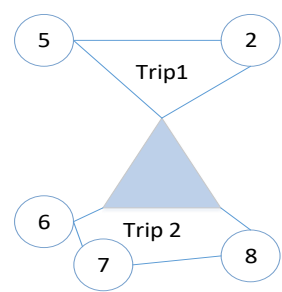

7

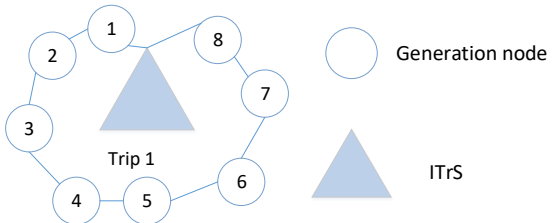

(b) 


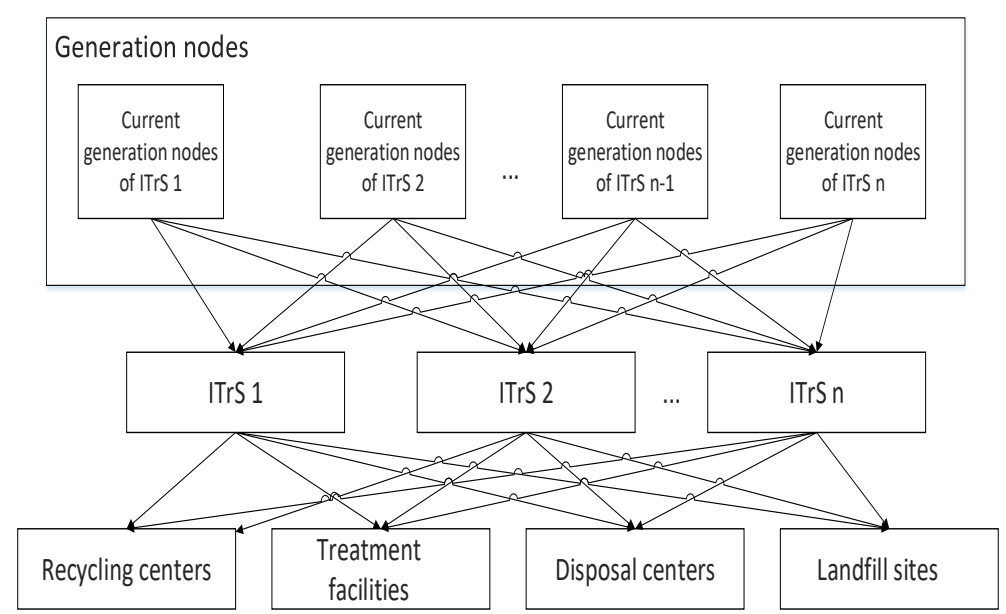

(c)

Fig.1 a) Graphical representation for the current MSW collection problem, b) An illustration of the SMTP-

\section{Routing and redesign social scores}

Multi-disciplinary and multi-stakeholders' attributes of systems make measurement and controlling all aspects of social issues impossible (Hosseinijou et al. 2014; Mirdar Harijani et al. 2017).

For social impact assessment of redesign and routing operations in the proposed model, the first guidelines for SLCA of UNEP/SETAC (UNEP/SETAC 2009) is used with some modifications. The details of extended SLCA methodology are shown in Fig.2.

The developed SLCA methodology includes four main steps: Goal and scope definition, Life cycle inventory analysis, Life cycle impact assessment and Life cycle interpretation. 
About the first step, the goal is to assess the social scores of the routing and redesign system and the scope facilities.

In the second step, the result should be some inventory indicators in order to reach the goal mentioned in previous step. The guidelines of UNEP/SETAC (UNEP/SETAC 2009) includes five stakeholder groups and further 31 assessment subcategories introduced through international consensus and presented to the experts including managers, engineers, workers, consumers and local communities. The goal and scope are explained and based on their opinions selected impact subcategories by stakeholders and experts who have more influence on stakeholders are presented in Table 2 in routing and redesign section respectively. In order to measure the score of facilities, 21 and 16 inventory indicators are developed for routing and 

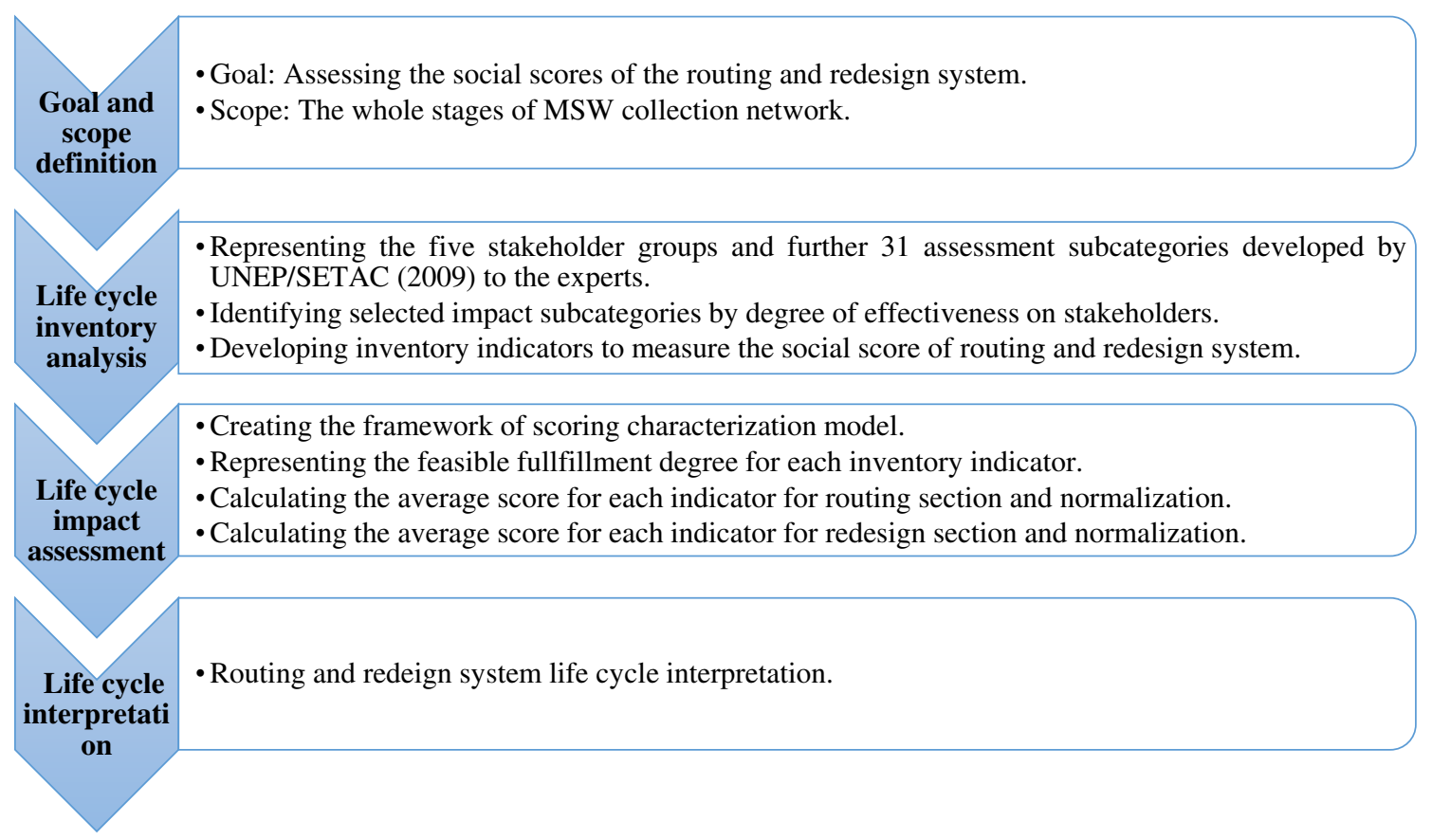

Fig.2 Steps of the proposed SLCA methodology for calculating the social score of routing and redesign system

The third step calculates the social score of routing and redesign section using a characterization model

which is based on a scoring system. For each subcategory, there are inventory indicators and measurement

guidelines to assess life cycle impacts. Scoring system assigns a value of $\left\{1.2 \ldots . m_{i}\right\}$ for inventory indicator $i$ for fulfillment degree of the social criteria, respectively, the lowest level to highest fulfillment

level. Answers given by each stakeholder interviewed regarding fulfillment will be transformed into these

values. The number of all the interviewed stakeholders is $n$. By considering that $s_{i j}$ is the selected score of

$$
\bar{s}_{i}=\frac{\sum_{j=1}^{n} s_{i j} / n}{m_{i}}
$$


The social score for the indicator $i\left(\bar{s}_{i}\right)$ will be a decimal number between 0 and 1 . For calculating the final

social score of routing it is necessary to normalize all average scores of 21 indicators as presented in

$$
S^{s c r}=\sum_{i=1}^{21} \alpha_{i} \bar{s}_{i}
$$

The $\alpha_{i}$ coefficients show the importance weight of indicator $\mathrm{i}$ and their summation is equal to one. In addition, the selected impact subcategories and 16 developed inventory indicators for the redesign system are presented in Table 2. Similarly, redesign social score is calculated over the above procedure.

The Fourth step is life cycle interpretation. The results indicate that the routing system have higher positive social impacts than redesign system. 
Table 2 Selected impact subcategories and developed inventory indicators for the routing and redesign system (Aparcana and Salhofer 2013)

\begin{tabular}{|c|c|c|c|c|}
\hline Stakeholder & Selected subcategories & Inventory indicators & $\begin{array}{l}\text { routing } \\
\text { system }\end{array}$ & $\begin{array}{l}\text { redesign } \\
\text { system }\end{array}$ \\
\hline \multirow{13}{*}{ Worker } & \multirow{7}{*}{ Health and safety } & Absence of working accidents & $\checkmark$ & $\checkmark$ \\
\hline & & Vaccination for workers & $\checkmark$ & $\checkmark$ \\
\hline & & Training programs regarding preventive measures & $\checkmark$ & $\checkmark$ \\
\hline & & Formal policy about health and safety for workers & $\checkmark$ & $\checkmark$ \\
\hline & & Access to medical centers for workers & $\checkmark$ & $\checkmark$ \\
\hline & & Access to preventive equipment for workers in prevalence situation & $\checkmark$ & \\
\hline & & Absence of disease for workers & $\checkmark$ & $\checkmark$ \\
\hline & Child labor & Absence of child labor & $\checkmark$ & $\checkmark$ \\
\hline & \multirow{2}{*}{ Fair salary } & Regular payment for workers & $\checkmark$ & $\checkmark$ \\
\hline & & Absence of non-agreed income deductions & $\checkmark$ & $\checkmark$ \\
\hline & \multirow{2}{*}{ Working hour } & Doing of overtime agreed in working contracts & $\checkmark$ & \\
\hline & & Overtime balance between workers & $\checkmark$ & \\
\hline & Social security & Existence of social security & $\checkmark$ & \\
\hline \multirow{4}{*}{ Customer } & \multirow{3}{*}{ Health and safety } & Satisfaction of cleaning of containers & $\checkmark$ & \\
\hline & & Satisfaction about pollution & $\checkmark$ & \\
\hline & & Satisfaction of collection frequency & $\checkmark$ & \\
\hline & Feedback mechanism & Existence of a reporting system for suggestions & $\checkmark$ & \\
\hline \multirow{6}{*}{ Local community } & Local employment & Creating job opportunities & $\checkmark$ & $\checkmark$ \\
\hline & \multirow{2}{*}{ Delocalization } & Reduce in housing prices & & $\checkmark$ \\
\hline & & Willingness to continue living in the district & & $\checkmark$ \\
\hline & Safe and healthy living conditions & Living satisfaction & & $\checkmark$ \\
\hline & Contribution to economic development & Progress of annual redesign cost /annual revenue index & & $\checkmark$ \\
\hline & Access to material resources & Accessibility to containers & $\checkmark$ & \\
\hline Society & Economic development & Progress of annual cost /annual revenue index & $\checkmark$ & $\checkmark$ \\
\hline
\end{tabular}




\begin{tabular}{|l|l|l|c|}
\hline & Prevention of armed conflicts & Reduce in number of dissatisfaction calls & $\checkmark$ \\
\hline Value chain actors & Fair competition & Formal policy for selecting contractors & $\checkmark$ \\
\hline
\end{tabular}


Problem assumptions are as follows: Customer's demand for waste collecting is deterministic and known.

Potential location for establishing new ITrS or aggregation with existing ITrS is given. Each customer is

Ex Set of existing ITrSs in existing network

$K_{1} \quad$ Set of vehicles, $K_{1}=\{1 \ldots . N V\}$

$K_{2} \quad$ Set of Semitrailers, $K_{2}=\{1 \ldots . k\}$

$P \quad$ Set of treatment, recycling and disposal facilities, $P=\{1 \ldots . p\}$ 
$f r_{e i}$ Relocation cost (USD) of existing ITrS $e$ to the aggregated location $i, e \in E x . i \epsilon I$

$f m_{i} \quad$ Fixed storage cost (USD) of existing ITrS $i$ independent of its capacity, $i \epsilon I$

$f s_{e} \quad$ Saving cost (USD) from closure of ITrS $e, e \epsilon E x$

fc Unit overhead costs (USD/year) of vehicles

$c_{k 1} \quad$ Unit traveling costs (USD/(m* Kg)) of vehicles, $k_{1} \in K_{1}$

$c_{k 2} \quad$ Unit transferring costs with collected MSW (USD/(m*kg)) of semitrailer, $k_{2} \in K_{2}$

$d_{i j} \quad$ Distance $(\mathrm{m})$ between node $i$ and $j, i \in I \cup J . j \in I \cup J$

$t_{i j} \quad$ Traveling time (min) between node $i$ and $j, i \in I \cup J . j \in I \cup J$

$D_{k_{1}} \quad$ Maximum operating time (min) of vehicles, $k_{1} \in K_{1}$

$W \quad$ An upper bound for number of vehicle trips, $k_{1} \epsilon K_{1}$

$q_{j} \quad$ Daily demand (kg) of customer $j$

$Q_{k_{1}} \quad$ Vehicle's capacity $(\mathrm{kg}), k_{1} \in K_{1}$

$Q_{k_{2}} \quad$ Semitrailer's capacity $(\mathrm{kg}), k_{2} \in K_{2}$

$F_{T} L^{m}$ Coefficient of increase in emission $m$ when semitrailers travel Full-Truck-Load (FTL) 
$\Omega^{m}$ Amount $\left(\mathrm{kg} /\left(\mathrm{kg}^{*} \mathrm{~m}\right)\right)$ of emission of type $m$ from MSW transferring by

$€_{i}^{s c l} \quad$ Normalized weight of social criteria for establishment of $i$ 


\section{Objective function}

Minimize COST $=\sum_{j \in I \cup J} \sum_{i \epsilon I \cup J} \sum_{k \epsilon k_{1}} \sum_{r \epsilon R} \sum_{t \epsilon T} d_{i j} c_{k_{1}} q_{j t} x_{i j}^{k r t}$

$+\sum_{t \epsilon T} \sum_{k \epsilon k_{2}} \sum_{i \epsilon I} \sum_{p \epsilon P} d_{i p} c_{k_{2}}\left(\alpha_{i p}^{k t}+1\right)$

$+\sum_{e \in E x} \sum_{i \in I} f r_{e i} z_{e i}$

$+\sum_{i \in E x} f m_{i} z_{i i}+\sum_{i \in N} f m_{i} w_{i}$

$-\sum_{j \in E x}\left[f s_{j}\left(1-\sum_{i \in I} z_{j i}\right)\right.$

$\left.+f m_{j} \sum_{\{i \epsilon E x . i \neq j\}} Z_{j i}\right]$

$+\sum_{i \in I} f c \times s_{i}$

$+\sum_{m \in M} e c_{m} \times$

$\left[\sum_{j \in I \cup J} \sum_{i \epsilon I \cup J} \sum_{k \epsilon k_{1}} \sum_{r \in R} \sum_{t \epsilon T} d_{i j} \Psi^{m} x_{i j}^{k r t}\right.$

$+\sum_{t \epsilon T} \sum_{k \epsilon k_{2}} \sum_{i \epsilon I} \sum_{p \epsilon P} \Omega^{m} d_{i p} \times F T L^{m} \times \alpha_{i p}^{k t}$

$\left.+\sum_{t \epsilon T} \sum_{k \epsilon k_{2}} \sum_{i \epsilon I} \sum_{p \epsilon P} \Omega^{m} d_{i p} \alpha_{i p}^{k t}\right]$ 
The objective function is to minimize the cost (COST) as described by Eq. (4). It consists of two parts to tackle two dimensions of sustainability.

Minimize $C O S T=E C O C O S T+E N V C O S T$

ECOCOST is presented in Eq. (5).

$E C O C O S T=T P C O S T+T F C O S T+R C O S T+M C O S T-S C O S T+F V C O S T$

TPCOST or the routing cost is calculated based on the distance matrix, as Eq. (6). Additional information on how to calculate $q_{j t}$ is provided in appendix A.

$T P C O S T=\sum_{j \in I \cup J} \sum_{i \in I \cup J} \sum_{k \epsilon k_{1}} \sum_{r \in R} \sum_{t \epsilon T} d_{i j} c_{k_{1}} q_{j t} x_{i j}^{k r t}$

TFCOST is waste transferring costs between ITrSs and treatment, recycling, and disposal facilities, as shown in Eq. (7). The coefficient is referred to as returning cost from treatment, recycling disposal facilities 239 to ITrSs when the semitrailers are empty.

$T F C O S T=\sum_{t \epsilon T} \sum_{k \epsilon k_{2}} \sum_{i \epsilon I} \sum_{p \epsilon P} d_{i p} c_{k_{2}}\left(\alpha_{i p}^{k t}+1\right)$

RCOST is given by Eq. (8). The equation represents the relocation cost of an existing ITrS to a new or another existing ITrS.

$R \operatorname{COST}=\sum_{e \epsilon E x} \sum_{i \in I} f r_{e i} z_{e i}$

MCOST is fixed maintenance costs of a new or an existing ITrS including insurance, taxes, and renting costs, as described in Eq. (9). 
$S \operatorname{COST}=\sum_{j \in E x}\left[f s_{j}\left(1-\sum_{i \epsilon I} z_{j i}\right)+f m_{j} \sum_{\{i \in E x . i \neq j\}} z_{j i}\right]$

$F V C O S T=\sum_{i \in I} f c \times s_{i}$

ENVCOST is the total environmental cost caused by waste transportation by vehicles and semitrailers. As shown in Eq. (12) it consists of three parts. Transportation and transferring wastes could result in GHG emissions. GHG emissions associated with the collection routes and the second echelon of the network produced by semitrailers are measured through ENVCOST. The environmental cost of emission $m$ through the collection phase is calculated by the first term in Eq. (12). Moreover, the environmental cost of emission $m$ from waste transportation by semitrailers when they are traveling FTL is calculated by the second term.

$$
\begin{aligned}
& \sum_{m \in M} e c_{m} \times\left[\sum_{j \epsilon I \cup J} \sum_{i \epsilon I \cup J} \sum_{k \epsilon k_{1}} \sum_{r \epsilon R} \sum_{t \epsilon T} d_{i j} \Psi^{m} x_{i j}^{k r t}\right. \\
& +\sum_{t \epsilon T} \sum_{k \epsilon k_{2}} \sum_{i \epsilon l} \sum_{p \epsilon P} \Omega^{m} d_{i p} \times F T L^{m} \times \alpha_{i p}^{k t} \\
& \left.+\sum_{t \epsilon T} \sum_{k \epsilon k_{2}} \sum_{i \epsilon I} \sum_{p \epsilon P} \Omega^{m} d_{i p} \alpha_{i p}^{k t}\right]
\end{aligned}
$$

\section{Constraints}


The constraints are divided into four main components which are related to the generation nodes, vehicles,

\section{Generation node's constraints}

$\sum_{k \epsilon k_{1}} \sum_{r \in R} \sum_{t \in T} y_{j}^{k r t} \geq 1$

$j \epsilon J$

Constraints (13) ensure that every generation node is served at least once in a given period.

$\sum_{k \epsilon k_{1}} \sum_{r \epsilon R} y_{j}^{k r t} \leq 1$

$j \epsilon J . t \epsilon T$

In contrast, Constraints (14) emphasize that every generation node must be served at most once in each day of a certain period.

$\sum_{i \in I \cup J} x_{i j}^{k r t}=y_{j}^{k r t}$

$j \epsilon J . k \epsilon k_{1} . r \in R . t \epsilon T$

Constraints (15) consider the relation between $x_{i j}^{k r t}$ and $y_{j}^{k r t}$ variables.

$\sum_{i \in I \cup J} x_{i e}^{k r t}=\sum_{j \in I \cup J} x_{e j}^{k r t}$

$e \epsilon I \cup J . k \epsilon k_{1} \cdot r \in R \cdot t \epsilon T$

Constraints (16) ensure the flow conservation for generation node and ITrS.

$\sum_{k \epsilon K_{1}} \sum_{r \in R} y_{j}^{k r t} \leq \sum_{\hat{t}} \sum_{\hat{k} \epsilon K_{1}} \sum_{\dot{r} \epsilon R} y_{j}^{k \dot{k} \dot{t}}$

$j \in J, t \in T-1 . t<t$

Constraints (17) indicate that the demands are met for the entire planned period.

$\sum_{j \in I \cup J} q_{j t} y_{j}^{k r t} \leq Q_{k_{1}}$ $k \in k_{1} . r \in R . t \epsilon T$

Constraints (18) ensure the total MSW collected during a trip should not exceed the vehicle's maximum capacity. 
$\sum_{j \epsilon J} q_{j t} x_{e j}^{k r t}+\sum_{j \epsilon J} \sum_{i \epsilon J} q_{j t} x_{i j}^{k r t}=T a k_{e}^{k r t}$

$\sum_{k \epsilon K_{1}} \sum_{r \in R} T a k_{i}^{k r t}=\sum_{k \in K_{2}} \sum_{p \in P} \alpha_{i p}^{k t}$

$i \epsilon I, t \in T$

Constraints (20) and (21) ensure that the inlet flow to each ITrS (total daily waste collected) and the outlet flow to the ITrSs (to processing plants) must be equal.

$\sum_{e \epsilon E x} z_{e i} \leq|E x| z_{i i}$

$i \in E x$

$\sum_{e \in E x} z_{e i} \leq|E x| w_{i}$

$i \epsilon N$

$\sum_{i \in E X \cup N} z_{e i} \leq 1$

$e \in E x$

Constraints (22), (23), and (24) are related to the redesign and relocation of ITrSs. Constraints (22) state

that the capacity of an existing ITrS cannot be relocated to the capacity of another existing ITrS unless that

ITrS remains open. Constraints (23) state that the capacity of an existing ITrS can not be relocated to another

new ITrS unless that new ITrS has been established. In Constraints (24), all options for an existing ITrS

$z_{e i} \leq z_{e e}$

$e \in E x, i \in N$

Constraints (25) indicate that if an existing and a new ITrS wish to be integrated into a new ITrS site, the existing ITrS must be pre-established. 
$\sum_{i \in \mathrm{I}} s_{i}=N V$

Constraints (28) and (29) indicate the relation between the number of vehicles that should be allocated to

ITrSs and the number of total existing vehicles.

$\sum_{i . v_{i} \in S} \sum_{j, v_{j} \in S} x_{i j}^{k r t} \leq|S|-1$

After leaving the ITrS, each vehicle could only visit a generation node on its trip and the return trip to the 
$x_{i j}^{k r t} \leq \sum_{j \in I \cup J} \sum_{i \epsilon I} x_{i^{\prime} j}^{k r t}$

$i \epsilon J . j \epsilon J . k \epsilon K_{1} . r \in R . t \epsilon T$

Constraints (35) indicate that if the vehicle wishes to have a trip that serves more than one customer or in the network there is an edge connecting two customers, the vehicle must begin its trip from ITrS.

$\sum_{s c r \epsilon S C R} \sum_{t \in T} \sum_{k \epsilon K_{1}} \sum_{r \in R} \sum_{j \epsilon J} S^{s c r}$

$\times £_{j . k . r . t}^{s c r} \times y_{j}^{k r t}$

$+\sum_{s c l e S C L} \sum_{e \epsilon E x} \sum_{i \epsilon I} S^{s c l} \times £_{e i}^{s c l} \times z_{e i}$

$+\sum_{s c l e S C L} \sum_{i \epsilon N} S^{s c l} \times €_{i}^{s c l} \times w_{i} \geq \Delta$

Finally, Constraints (36) consider the social dimension of sustainability in routing and redesign of the

network. The social score of the network should be greater or equal than a specific value calculated based

on trial and error method with considering the local governments and the responsible organizations for

MSWMSs.

$x_{i j}^{k r t} \in\{0.1\}$

$i \in I \cup J . j \in I \cup J . k \epsilon k_{1} . r \in R . t \epsilon T$

$y_{j}^{k r t} \epsilon\{0.1\}$

$j \epsilon J . k \epsilon k_{1} \cdot r \in R . t \epsilon T$

$s_{i} \in N$

$i \epsilon I$

$s_{i}^{t} \in N$

$i \epsilon I . t \epsilon T$

$\alpha_{i p}^{k t} \geq 0$

$i \epsilon I . p \in P . t \in T$

$z_{e i} \in\{0.1\}$

$e \in E x . i \epsilon l$

$w_{i} \in\{0.1\}$

$i \epsilon I$

$\operatorname{Tak}_{e}^{k r t} \geq 0$

$e \epsilon I, t \in T \cdot r \in R . k \in K_{1}$

Constraints (37) - (44) include the binary and non-negative requirements for the variables. 


\section{Case study description}

To represent the applicability of the SMTP-reLRP model, a real case study is used, related to Tehran, the

capital of Iran. Tehran waste management organization (TWMO) is responsible for collecting, separating,

and processing MSW of all 22 districts but the collection operation is outsourced to 58 contractors (TWMO

2020). Here the case is related to the contractor who collects the MSW of district 8, region 2, Haft Howz

neighborhood, which discharges the collected MSW in Beyhaghi ITrS. Currently, MSW collection of this

area is done by two vehicles during the day. The approximate location of MSW containers (The main

version of TMWO can be seen in appendix B) and the current collection route of the vehicles are shown in

Fig.3(b) and Fig.3(c). Each vehicle performs some trips every day and the patterns of routes in all trips are

similar for each vehicle. The drivers repeat their trips at least twice in 24 hours. The MSW container numbers in Fig.3(a) indicates the order of visits and Fig.3(b) and Fig.3(c) demonstrate current vehicle 1 and 2 route patterns implemented by the contractor respectively.

The number of MSW containers in the considered region is 69 with a maximum capacity of $55 \mathrm{~kg}$. About the daily demand parameter in the SMTP-reLRP model, the data is derived from the weighing system located in Beyhaghi ITrS. By examining daily generated MSW in 2018, the average daily demands for the route of vehicles 1 and 2 are $664 \mathrm{~kg}$ and $456 \mathrm{~kg}$ respectively.

As the containers are located in a region with the same geographical, historical, cultural, and economic characteristics, it is realistic to assume the daily demands of customers in a route are equal. Therefore, daily demand of MSW containers in the route of vehicle 1 and 2 is $40 \mathrm{~kg}$ and $41 \mathrm{~kg}$ respectively. Both vehicles are similar and have 6 tons of capacity. Weekly fixed and variable cost are 148.79 UC or Unit Cost (Because the costs of the contractors are confidential, the exact unit is not provided) and $4.6^{*} 10 \mathrm{e}-7 \mathrm{UC}$ per meter 
For obtaining the exact solution, NEOS solver for optimization is used online (Gropp and Moré 1997;

Czyzyk et al. 1998; Dolan 2001). Within the NEOS server, IBM ILOG CPLEX Optimizer is applied.

CPLEX uses a branch and cut algorithm which solves a series of LP sub problems and can obtain the exact

solution for the problem with maximum of 1000 variables and 1000 constraints. Here with 69 customers,

there are one million constraints. For solving this problem, square adjacency matrix $A$ [|customers|] is

defined. It is a zero-one matrix with zeros on its diagonal since edges from a customer node to itself are not

allowed. Other elements of $A_{i j}$ are one when there is just one choice for continuing the trip which is an

edge from customer node $i$ to customer node $j$. In the streets, it is usual to have just one choice for servicing

nodes that do not determine the optimal route. For example, for the route of vehicle 1 , as the container

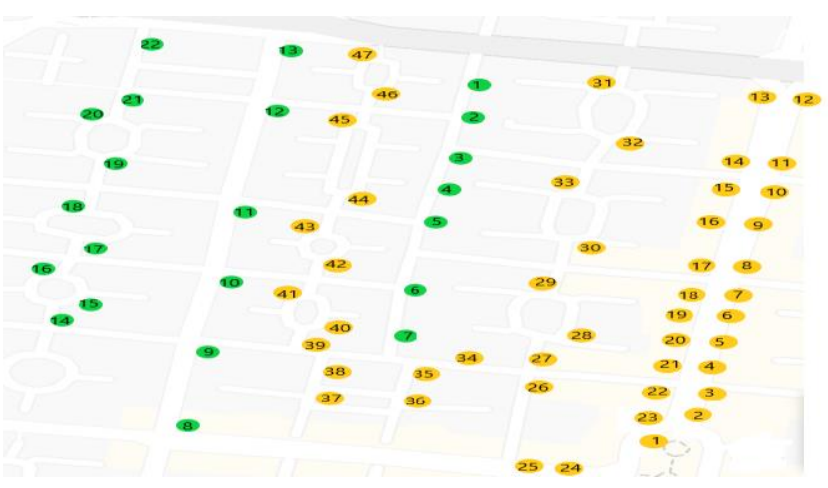

(a) 


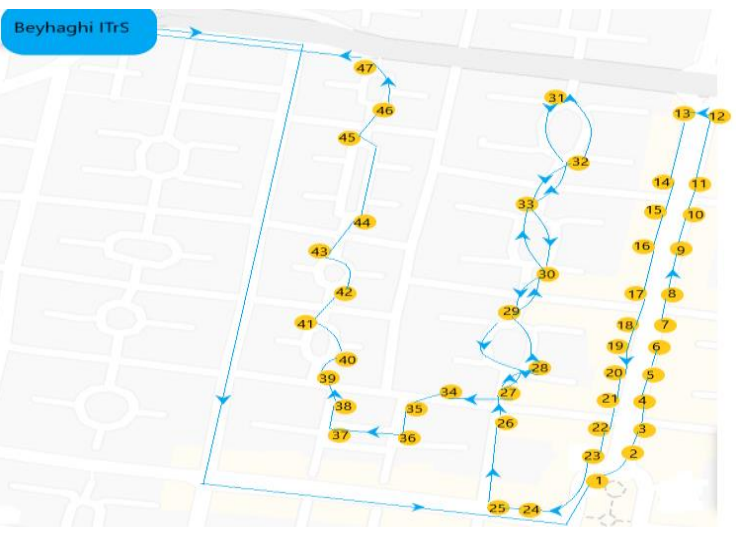

(b)

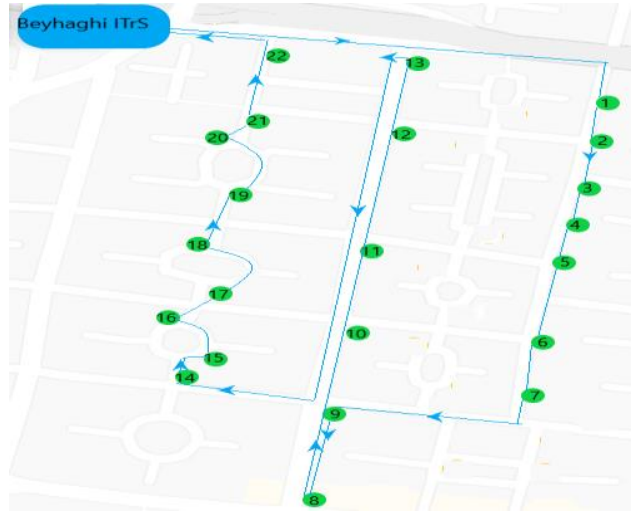

(c)

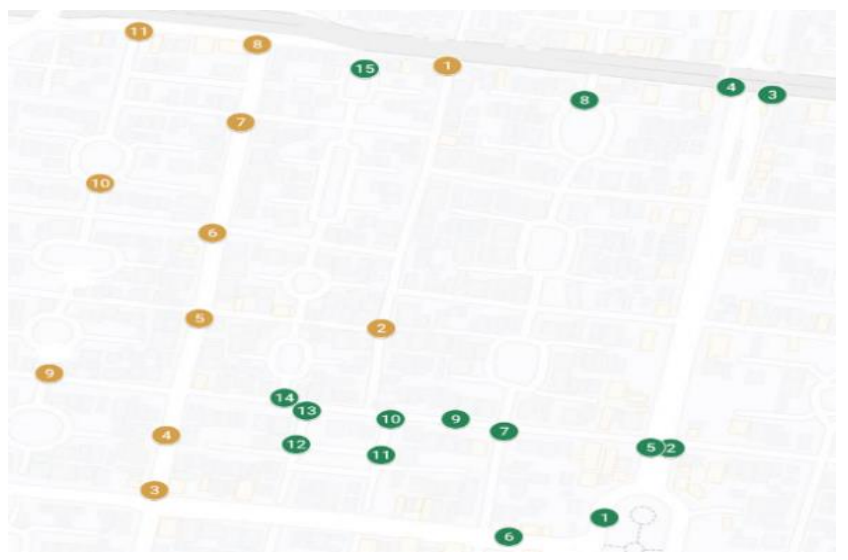

(d)

Fig.3 a) Current approximate MSW container location, b, c) daily route pattern by vehicles, d) 26 key MSW

Semitrailer capacities for transferring MSWs from ITrSs to the processing plants are 22 tons with 5.6*10e-

7 UC variable cost per $\mathrm{kg}$ and per meter. The candidate ITrS for considering the redesigning options is

Banihashem ITrS. The saving cost of Beyhaghi ITrS closure is considered 7474 UC.

Aradkooh waste processing plant which is the biggest one in Tehran is considered a processing plant in the 
between nodes are obtained from Google Maps. All the parameters are uploaded on given link:

For solving the problem presented of a real case study, some main parameters of the $S M T P$-reLRP model

\section{Environmental parameters}

About environmental costs, four main types of emissions are considered, i.e., $\mathrm{CO}_{2}, \mathrm{SO}_{2}, \mathrm{NO}_{\mathrm{x}}$, and VOC

emissions. The unit environmental cost and the amount of emissions caused by transportation and

\section{Social parameters}

About social constraints, at first, the inventory indicators for the social score of routing and redesign operation were scored by 43 people, including employees of TWMO and contractors in charge of waste

collection. Secondly, for routing and redesign operation, the summation of normalized weight is 0.6 and 
the social score of the redesigning. Considering economic and environmental function Fig.4(a) indicates

Finally, about the social score for routing and relocation, Fig.4(a) indicates that the diagram related to $S^{s c r} . S^{s c l}=1$ has the most feasible solutions. In other words, the higher the scores provided by experts, the higher probability of finding the optimal solution. These values are $S^{s c r}=0.63$ and $S^{s c l}=0.62$ with

\section{Results and discussion}

Fig.4(b) shows the results of solving the SMTP-reLRP model for the case study. As the real distances

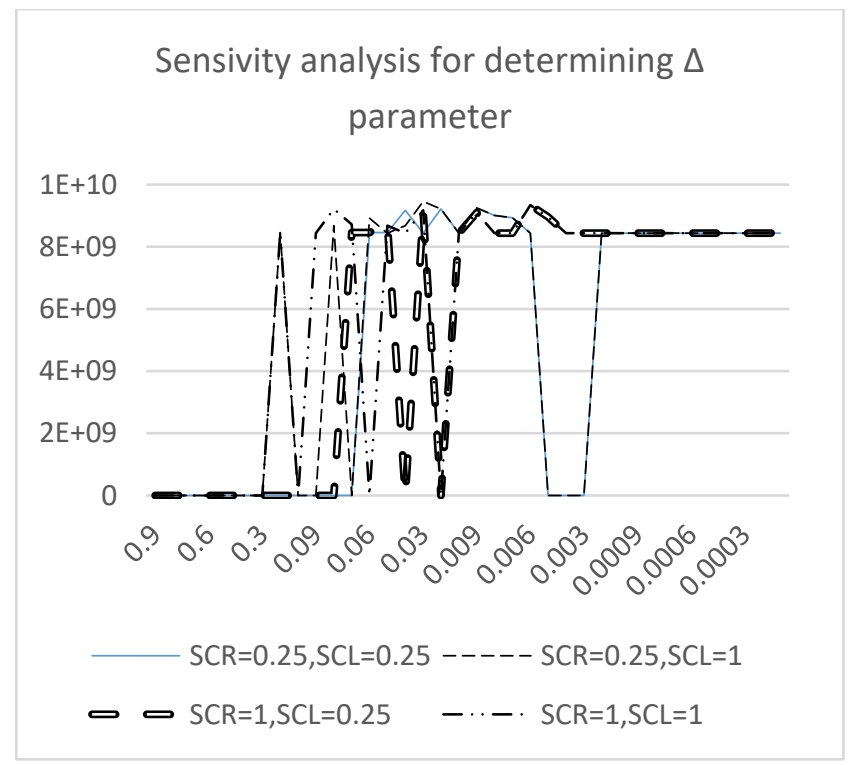


(a)

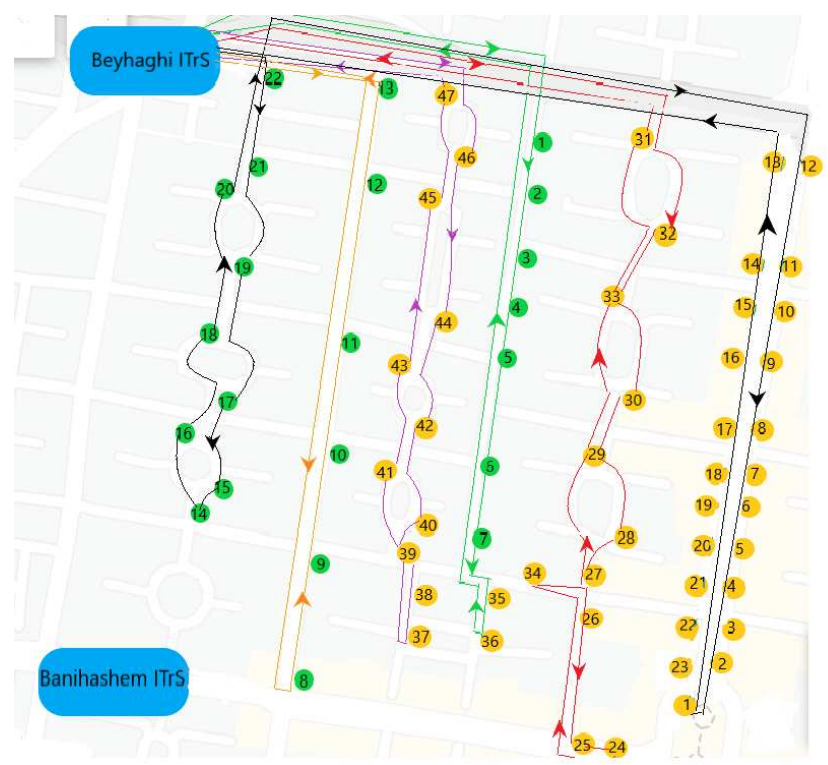

(b)

Fig.4 a) Acceptable range of $\Delta$ parameter via economic and environmental function consideration, b) Optimal routing

Daily trips of vehicles and tour duration for the optimal solution are provided in Table 3. Optimal solution indicates that vehicles should begin their trips from Beyhaghi and vehicles 1 and 2 can cover all weekly requirements for waste collection with 3 and 2 trips respectively.

The results show that for the first research question, there is no need to relocate Beyhaghi ITrS for the case.

As stated before, for Tehran case, TWMO is responsible for collecting, separating, and processing MSW of all 22 districts but the collection operation is outsourced to 58 contractors. The results of solving the case are related to one of these contractors and for this contractor Beyhaghi is the best choice of being ITrS. 


\begin{tabular}{|c|c|c|c|c|c|}
\hline Tour & Day & Vehicle & Optimal route & $\begin{array}{c}\text { Traveled } \\
\text { distance }(\mathrm{km})\end{array}$ & $\begin{array}{l}\text { Tour duration } \\
\text { (min) }\end{array}$ \\
\hline 1 & 7 & 1 & $\begin{array}{l}\text { Beyhaghi-(22-21-20-19-18-17-16-15-14)(green)-12-11-10-9-8-7-6-5-4-3- } \\
\text { 2-1-23-22-21-20-19-18-17-16-15-14-13-Beyhaghi }\end{array}$ & 26 & 49 \\
\hline 2 & 7 & 1 & Beyhaghi-30-32-31-29-28-27-26-24-25-34-33-Beyhaghi & 17 & 28 \\
\hline 3 & 7 & 1 & Beyhaghi-(8-9-10-11-12-13) green-Beyhaghi & 13 & 26 \\
\hline 1 & 7 & 2 & Beyhaghi-(1-2-3-4-5-6-7) green-35-36-Beyhaghi & 17 & 27 \\
\hline 2 & 7 & 2 & Beyhaghi-47-46-45-44-43-42-41-40-39-38-37-Beyhaghi & 18 & 30 \\
\hline \multicolumn{4}{|c|}{ Optimal total traveled distance $(\mathrm{km})$} & \multicolumn{2}{|c|}{91} \\
\hline \multicolumn{4}{|c|}{ Current total traveled distance $(\mathrm{km})$} & \multicolumn{2}{|c|}{672} \\
\hline \multicolumn{4}{|c|}{ Weekly $\mathrm{CO}_{2}$ Emission reduction from transportation $(\mathrm{kg})$} & \multicolumn{2}{|c|}{447} \\
\hline \multicolumn{4}{|c|}{ Optimal total transferring distance $(\mathrm{km})$} & \multicolumn{2}{|c|}{94} \\
\hline \multicolumn{4}{|c|}{ Current total transferring distance $(\mathrm{km})$} & \multicolumn{2}{|c|}{685} \\
\hline \multicolumn{4}{|c|}{ Weekly $\mathrm{CO}_{2}$ Emission reduction from transferring $(\mathrm{kg})$} & \multicolumn{2}{|c|}{660} \\
\hline
\end{tabular}

It seems that by considering some/all of these contractors or changing system boundaries and solving the current Tehran ITrSs' structure there is no cooperative perspective between ITrSs as value chain actors.

ITrSs' structure. In other words, if the ITrSs as value chain actors work with cooperation, the result of

Besides, the comparison of the annual capacity of the ITrSs and the average annual amount of Tehran MSW generation rate indicates that the redesign of ITrSs will be more probable. The average daily amount of

Tehran MSW generation rate is about 9000 tons which equals $328 * \mathrm{e} 10+4$ tons in a year. According to the annual capacity of an ITrS which is $175^{*} \mathrm{e} 10+4$ tons, it seems that the existence of $11 \mathrm{ITrSs}$ is not cost- 
effective and revision in ITrS's numbers and locations could help to reduce the municipality operation costs

(TWMO 2020).

It should be noted the solution of the model is obtained with this assumption that only the revenues from the equipment sale are included in the saving cost from the closure of Beyhaghi ITrS (7474 UC). However,

About the second research question or allocation rule of waste generation points to the Beyhaghi ITrS and with comparison to existing MSW collection operation, routing pattern switched from two dimensions for each vehicle. The first dimension is the number of generation nodes which are visited in a trip for the vehicles. The second dimension will be the number of trips assigned to each vehicle in a day.

The third research question is about the collection frequencies for the generation points. The results indicate that for any generation node the optimum solution is the visiting and servicing them just once in a week. For the other research questions, about the best routes Fig.4(b) is shown and as a result costs minimization representation is investigated through solving the model with scenarios in which social and environmental consideration are ignored. In other words, to evaluate the impact of sustainability the SMTP-reLRP model is compared with three other possible models in Table 4: I) only economic aspect of sustainability is considered, II) the economic and environmental dimensions of sustainability are considered, III) the economic and social dimensions of sustainability are considered. Table 4 shows the comparison between the key results of the SMTP-reLRP model and the models (I), (II) and (III). The economic dimension of the sustainability is considered in all of them. The comparison of the SMTP-reLRP and model (I) indicates that model (I) leads to less COST and less social benefits. This denotes that the omitting the social 
Model (I) and model (II) have same solution for collecting MSW network. As the environmental costs are

Similarly, comparison of the SMTP-reLRP model and model (III) shows that the solutions of both are same.

For the case, involving the sustainability concept results in a sustainable solution with a higher social score factors. 


\begin{tabular}{|c|c|c|c|c|c|c|c|c|}
\hline \multirow[b]{2}{*}{ Model } & \multirow[b]{2}{*}{ Sustainability } & \multirow[b]{2}{*}{ Objective function } & \multirow[b]{2}{*}{$\begin{array}{l}\text { Subject to the constraints } \\
\text { set given by: }\end{array}$} & \multicolumn{5}{|c|}{ Sustainability dimensions } \\
\hline & & & & $\operatorname{cosT}(\mathrm{UC})$ & $\mathrm{ECOCOST}(\mathrm{UC})$ & ENVCOST(UC) & $\begin{array}{c}\text { Relocation social } \\
\text { score }\end{array}$ & $\begin{array}{c}\text { Routing social } \\
\text { score }\end{array}$ \\
\hline Current & Excluded & - & - & 3534941.42 & 794570.78 & 2740370.635 & 0.624 & 0.715 \\
\hline $\begin{array}{l}\text { SMTP-reLRP } \\
\text { model }\end{array}$ & Included & $\begin{array}{l}\text { Minimize ECOCOST and } \\
\text { ENVCOST }\end{array}$ & Eqs. (13) to (44) & 1186024.5 & 794536.64 & 391487.85 & 0.624 & 0.626 \\
\hline Model (I) & Excluded & ECOCOST & $\begin{array}{l}\text { Eqs. (13) to (35) and (37) } \\
\text { to (44) }\end{array}$ & 650324.12 & 650324.12 & - & 0.624 & 0.615 \\
\hline Model (II) & Excluded & $\begin{array}{l}\text { Minimize ECOCOST and } \\
\text { ENVCOST }\end{array}$ & $\begin{array}{l}\text { Eqs. (13) to (44) and (37) } \\
\text { to (44) }\end{array}$ & 961199.22 & 650324.12 & 310875.1 & 0.624 & 0.615 \\
\hline Model (III) & Excluded & Minimize ECOCOST & Eqs. (13) to (44) & 794536.64 & 794536.64 & - & 0.624 & 0.626 \\
\hline
\end{tabular}


To compare the result with the existing situation, Table 4 is presented. The weekly cost function has decreased 2348916 UC which equals to 122143679 UC in a year. $66 \%$ saving cost is obtained via finding optimal weekly collection frequency and finding the best redesign. Objective function, total traveled

Table 4 indicates that current collection operation suffers from a lot of inefficiency in terms of cost collection operation.

The proposed model considers three dimension of sustainability including economic, environmental and social aspect of MSW collection simultaneously and the results indicate that there are many inefficiencies

\section{Conclusion}

In this research, the SMTP-reLRP model for simultaneous consideration of three sustainability dimensions

with strategic, tactical, and operational issues in MSWMSs is introduced. Given the literature, this is the 
redesign and routing operations. To represent the $S M T P$-reLRP model applicability a real case study was sustainability factors.

For future research, involving the environmental factors about different collection frequency options, for example, the effect of collection frequency on attracting pests and leakage of leachate is suggested.

Declarations: 
Not applicable.

Competing interests

Funding

Not applicable.

Conceptualization, Methodology, Software: [Leila Mahdavi]. Data curation, Writing- Original draft preparation: [Leila Mahdavi]. Visualization, Investigation: [Leila Mahdavi, Mohsen Sajadieh:]. 
Aparcana, S., \& Salhofer, S. (2013). Development of a social impact assessment methodology for recycling systems in low-income countries. The International Journal of Life Cycle Assessment, 18(5), 1106-1115.

Asefi, H., \& Lim, S. (2017). A novel multi-dimensional modeling approach to integrated municipal solid waste management. Journal of cleaner production, 166, 1131-1143.

Asefi, H., Lim, S., \& Maghrebi, M. (2015). A mathematical model for the municipal solid waste location-routing problem with intermediate transfer stations. Australasian Journal of Information Systems, 19.

Asefi, H., Lim, S., Maghrebi, M., \& Shahparvari, S. (2019). Mathematical modelling and heuristic approaches to the location-routing problem of a cost-effective integrated solid waste management. Annals of Operations Research, 273(1-2), 75-110.

Babaee Tirkolaee, E., Abbasian, P., Soltani, M., \& Ghaffarian, S. A. (2019). Developing an applied algorithm for multi-trip vehicle routing problem with time windows in urban waste collection: A case study. Waste Management \& Research, 37(1_suppl), 4-13.

Ballou, R. H. (2007). The evolution and future of logistics and supply chain management. European business review.

Baptista, S., Oliveira, R. C., \& Zúquete, E. (2002). A period vehicle routing case study. European Journal of Operational Research, 139(2), 220-229.

Beltrami, E. J., \& Bodin, L. D. (1974). Networks and vehicle routing for municipal waste collection. Networks, 4(1), 65-94.

Czyzyk, J., Mesnier, M. P., \& Moré, J. J. (1998). The NEOS server. IEEE Computational Science and 504 Engineering, 5(3), 68-75.

Dolan, E. D. (2001). NEOS Server 4.0 administrative guide. arXiv preprint cs/0107034. 506

https://www.dropbox.com/scl/fi/agg0iyonwtq33iOpaiOnx/parameters.xlsx?dl=0\&rlkey=pjqfve 507 u6fs8c236vvyrrgq20j. 508

Edalatpour, M., Mirzapour Al-e-hashem, S., Karimi, B., \& Bahli, B. (2018). Investigation on a novel 509 sustainable model for waste management in megacities: A case study in tehran 510 municipality. Sustainable cities and society, 36, 286-301. 511

Erfani, S. M. H., Danesh, S., Karrabi, S. M., \& Shad, R. (2017). A novel approach to find and 512 optimize bin locations and collection routes using a geographic information system. $\quad 513$ Waste Management \& Research, 35(7), 776-785.

Farrokhi-Asl, H., Tavakkoli-Moghaddam, R., Asgarian, B., \& Sangari, E. (2017). Metaheuristics for a bi-objective location-routing-problem in waste collection management. Journal of Industrial and Production Engineering, 34(4), 239-252.

Ghiani, G., Laganà, D., Manni, E., Musmanno, R., \& Vigo, D. (2014). Operations research in solid 518 waste management: A survey of strategic and tactical issues. Computers \& Operations $\quad 519$ Research, 44, 22-32. 
Gropp, W., \& Moré, J. (1997). Optimization Environments and the NEOS Server in MD Buhmann and A. Iserles (eds.), Approximation Theory and Optimization. Cambridge University Press.

Hannan, M., Akhtar, M., Begum, R., Basri, H., Hussain, A., \& Scavino, E. (2018). Capacitated vehicle-routing problem model for scheduled solid waste collection and route optimization using PSO algorithm. Waste management, 71, 31-41.

Hosseinijou, S. A., Mansour, S., \& Shirazi, M. A. (2014). Social life cycle assessment for material selection: a case study of building materials. The International Journal of Life Cycle Assessment, 19(3), 620-645.

Matos, A. C., \& Oliveira, R. C. An experimental study of the ant colony system for the period vehicle routing problem. In International Workshop on Ant Colony Optimization and Swarm Intelligence, 2004 (pp. 286-293): Springer

Mirdar Harijani, A., Mansour, S., \& Karimi, B. (2017). A multi-objective model for sustainable recycling of municipal solid waste. Waste Management \& Research, 35(4), 387-399. $\quad 534$

Moghadam, M. A., Mokhtarani, N., \& Mokhtarani, B. (2009). Municipal solid waste management in Rasht City, Iran. Waste management, 29(1), 485-489.

P. Sanghatawatana, P. P., and M. Lohatepanont (2019). Redesign of Three-Echelon MultiCommodity Distribution Network. Eng. J, 23(1), 49-74.

Prodhon, C. (2011). A hybrid evolutionary algorithm for the periodic location-routing problem. European Journal of Operational Research, 210(2), 204-212.

Rabbani, M., Farrokhi-Asl, H., \& Asgarian, B. (2017). Solving a bi-objective location routing problem by a NSGA-II combined with clustering approach: application in waste collection problem. Journal of Industrial Engineering International, 13(1), 13-27.

Ramos, T. R. P., Gomes, M. I., \& Barbosa-Póvoa, A. P. (2014). Planning a sustainable reverse logistics system: Balancing costs with environmental and social concerns. Omega, 48, 60-74.

Shih, L.-H., \& Chang, H.-C. (2001). A routing and scheduling system for infectious waste collection. Environmental Modeling \& Assessment, 6(4), 261-269.

TWMO (2020). Statistics report on 2019. Tehran Waste Management Organization, Tehran municipality, Iran. http://pasmand.tehran.ir/. 
In Constraints (18), (20), and Objective function, $q_{j t}$ is the demand of customer $j$ on day $t$, which depends

$$
\begin{aligned}
q_{j t} & =q_{j}\left[t-\max _{l=1, \ldots, t-1}\left(\sum_{r \in R} \sum_{k \in k_{1}} y_{j}^{k r l} l\right)\right] \\
& =q_{j}\left[t-\phi_{j t}\right]
\end{aligned}
$$

$$
\phi_{j t=1, \ldots, t-1}=\max \left(\sum_{r \in R} \sum_{k \in k_{1}} y_{j}^{k r l} l\right)
$$

$\phi_{j t} \geq \sum_{r \in R} \sum_{k \in k_{1}} y_{j}^{k r l} l$

Note Constraints (47) and $\phi_{j t} \in N$ will be added to the main constraints. Constraints (30) greatly influence solving time which is a classic subtour elimination constraint for VRPs. Here a replaced formulation to overcome the limitations (Miller, Tucker et al. 1960) is derived and Equations (48), (49), and $\mu_{j} \geq 0$ is added to the model.

$$
\begin{array}{cc}
q_{j}\left[t-\phi_{j t}\right] \leq \mu_{j t} \leq Q_{k_{1}} & j \in J, t \in T \\
\mu_{i t}-\mu_{j t}+Q_{k_{1}} \sum_{k \epsilon k_{1}} \sum_{r=1}^{w} x_{i j}^{k r t} & \\
\quad+\left(Q_{k_{1}}-q_{i}\left[t-\phi_{i t}\right]-q_{j}\left[t-\phi_{j t}\right]\right) & \\
\times \sum_{k \epsilon k_{1}} \sum_{r=1}^{w} x_{i j}^{k r t} &
\end{array}
$$




$$
\leq Q_{k_{1}}-q_{j}\left[t-\phi_{j t}\right]
$$

It can be seen that Objective function and Constraints (18), (49) and (20) will be nonlinear. The following

$\phi_{j t} x_{i j}^{k r t}=w_{i j}^{k r t}$

$w_{i j}^{k r t} \leq \emptyset_{j t}$

$w_{i j}^{k r t} \leq M x_{i j}^{k r t}$

$w_{i j}^{k r t} \geq \emptyset_{j t}-\left(1-x_{i j}^{k r t}\right) \times M$

$w_{i j}^{k r t} \geq 0$ 


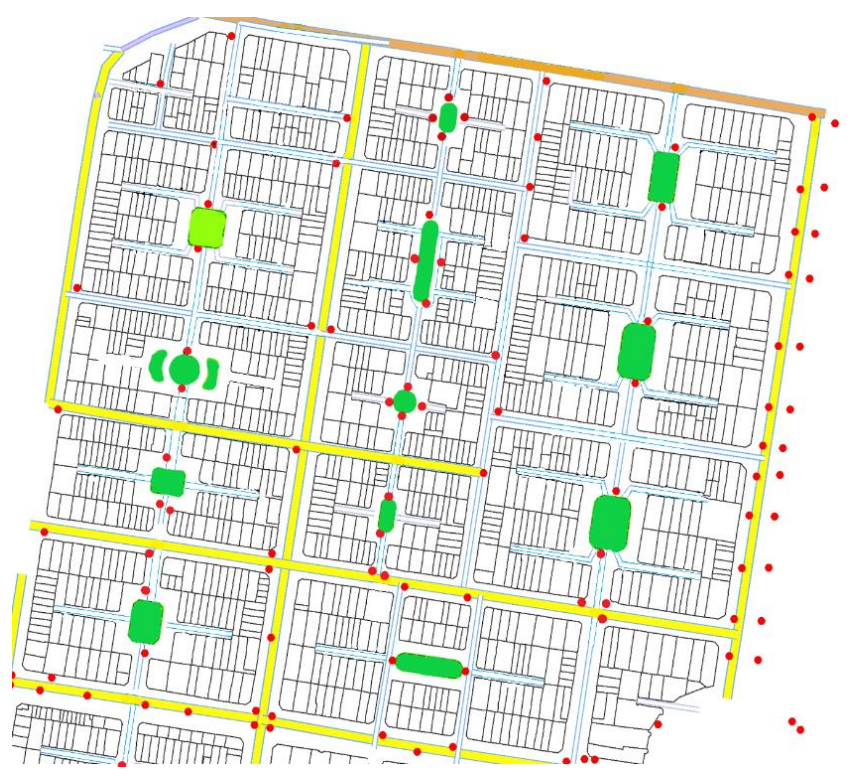

Fig. 5 MSW container's location map of Haft Howz neighborhood (TWMO 2020) 
Figures

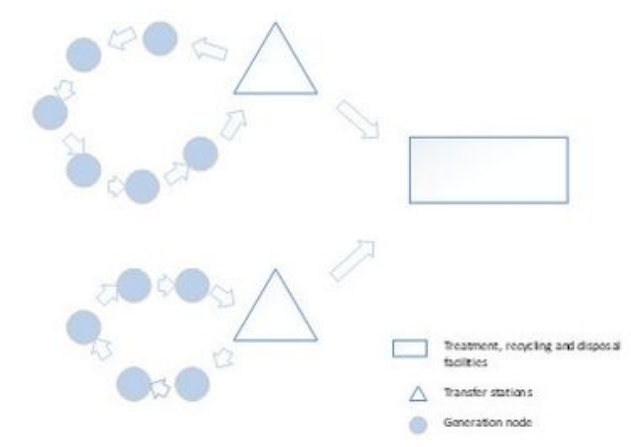

(a)
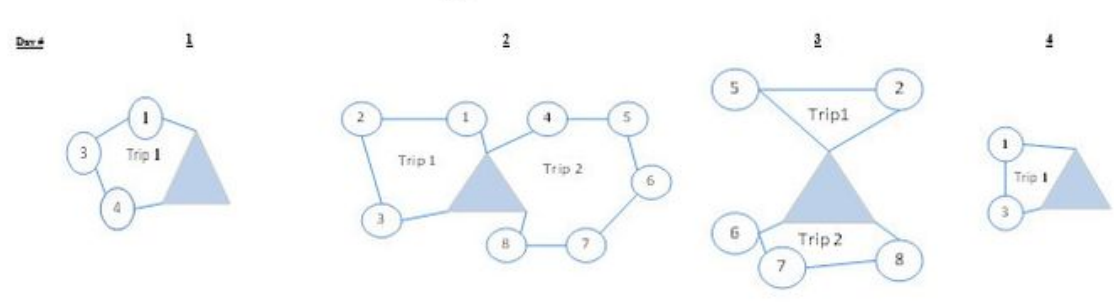

Dent
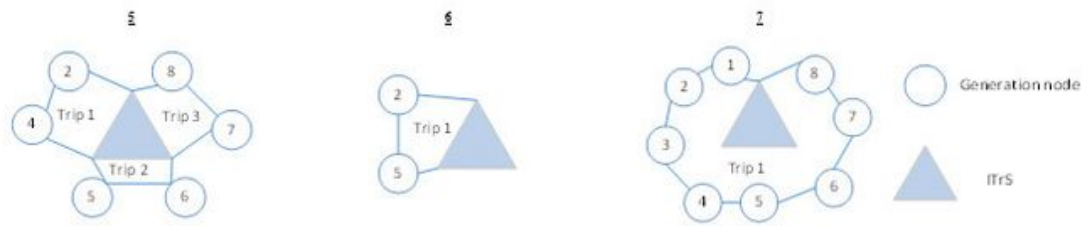

(b)

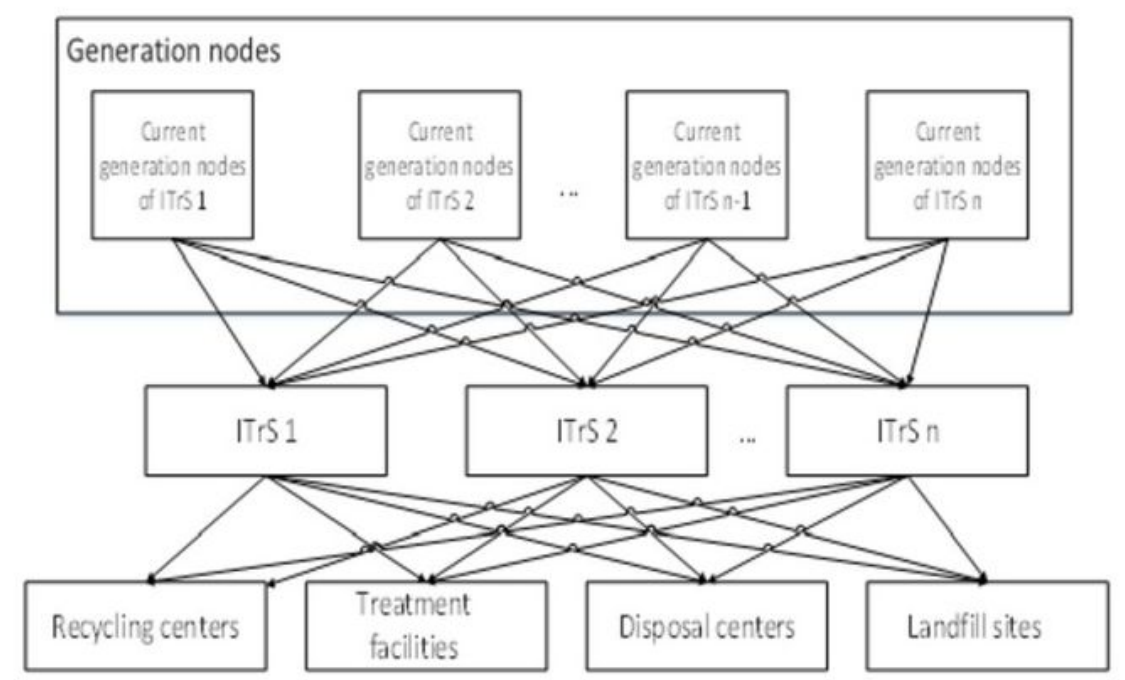

(c)

\section{Figure 1}

a) Graphical representation for the current MSW collection problem, b) An illustration of the SMTP-reLRP solution in a week, c) Cooperating municipal solid waste collection scheme 
- Goal: Assessing the social scores of the routing and redesign system.

- Scope: The whole stages of MSW collection network.

Goal and scope definition

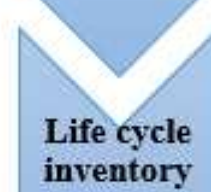
analysis

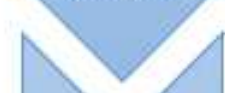

Life cycle

impact assessment

- Representing the five stakeholder groups and further 31 assessment subcategories developed by UNEP/SETAC (2009) to the experts.

- Identifying selected impact subcategories by degree of effectiveness on stakeholders.

-Developing inventory indicators to measure the social score of routing and redesign system.

- Creating the framework of scoring characterization model.

- Representing the feasible fullfillment degree for each inventory indicator.

- Calculating the average score for each indicator for routing section and normalization.

- Calculating the average score for each indicator for redesign section and normalization.

Life cycle $\cdot$ Routing and redeign system life cycle interpretation.

Figure 2

Steps of the proposed SLCA methodology for calculating the social score of routing and redesign system 


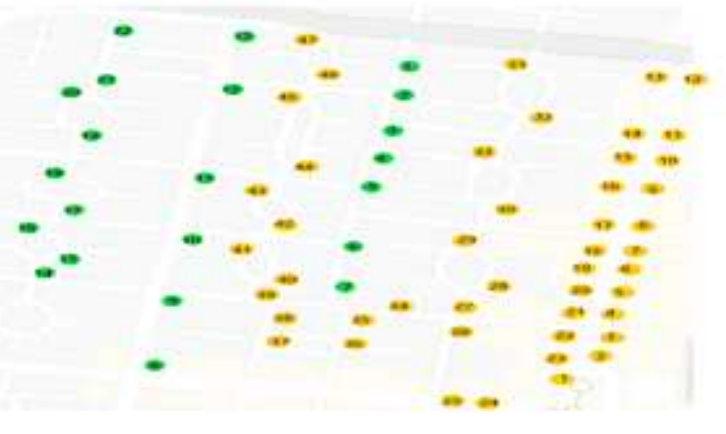

(a)

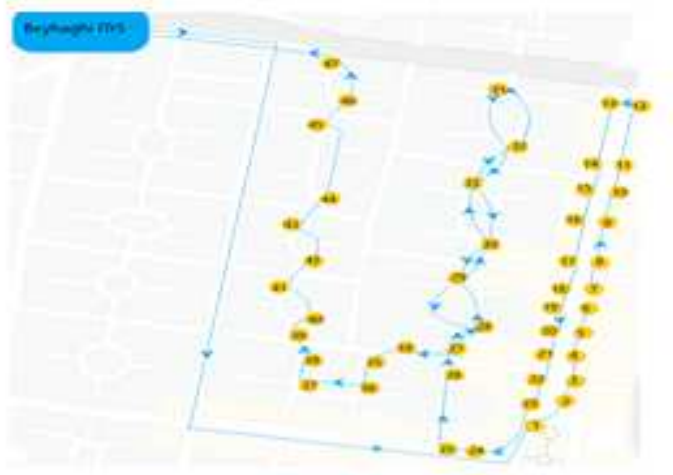

(b)

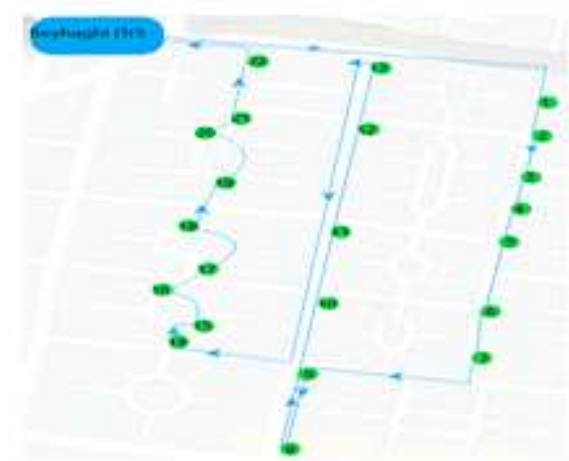

(c)

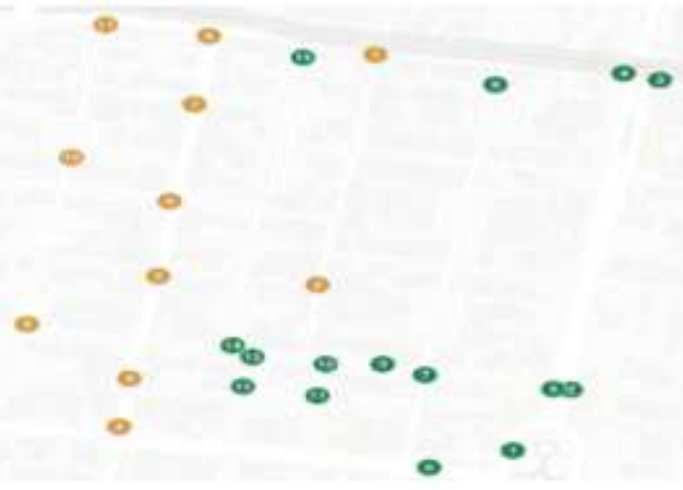

(d)

Figure 3

a) Current approximate MSW container location, b, c) daily route pattern by vehicles, d) 26 key MSW container nodes 


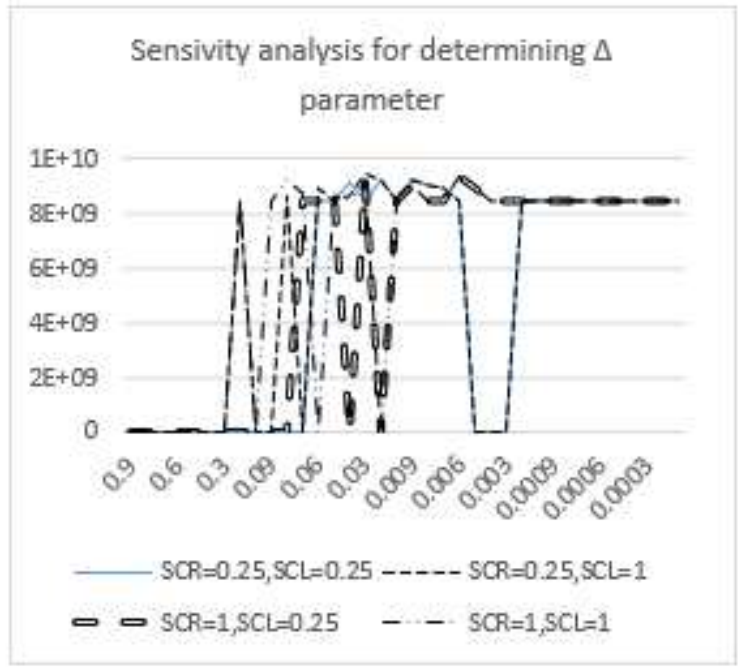

(a)

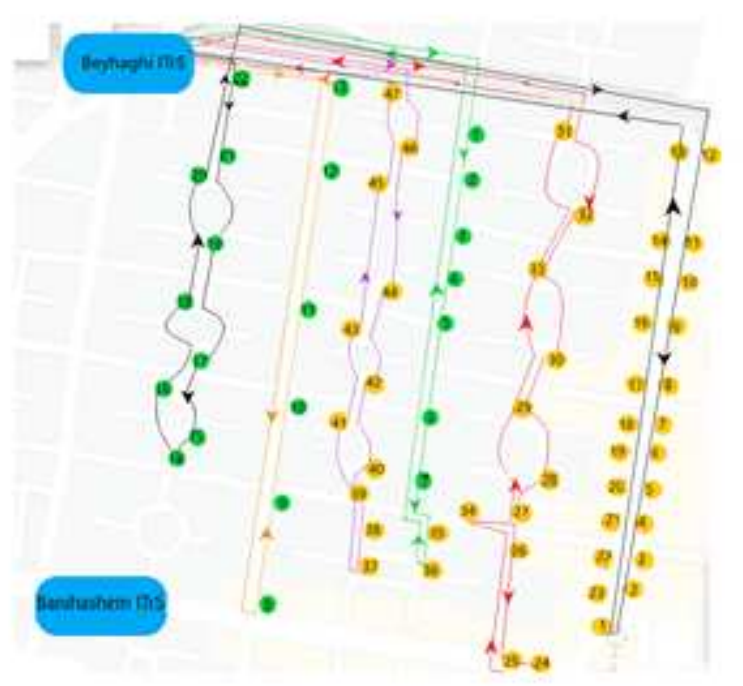

(b)

Figure 4

a) Acceptable range of $\Delta$ parameter via economic and environmental function consideration, b) Optimal routing and redesign for the case study 